\title{
UTILIZAÇÃO DE UM CLOROFILÔMETRO PORTÁTIL NA DETECÇÃO DO TEOR DE NITROGÊNIO EM Brachiaria decumbens
}

Mário Cupertino da Silva Júnior ${ }^{1}$, Francisco de Assis de Carvalho Pinto ${ }^{2}$, Daniel Marçal de Queiroz ${ }^{2}$, Darly Geraldo Sena Júnior ${ }^{3}$, Nerílson Terra Santos ${ }^{4}$

\section{RESUMO}

Com a variabilidade nutricional do solo, a adubação uniforme, a qual é praticada convencionalmente, pode proporcionar uma aplicação indevida, tornando-se ineficiente. Assim, a utilização de ferramentas que possam identificar essa variabilidade, pode auxiliar na aplicação diferenciada e localizada, permitindo que cada área receba a quantidade necessária de adubo. O objetivo deste trabalho foi utilizar um medidor de clorofila portátil (SPAD 502) para detectar diferentes status nutricionais ocasionados por doses de adubação nitrogenada diferenciada em Brachiaria decumbens. O presente trabalho foi desenvolvido em uma área com esta pastagem já estabelecida, no Setor de Forragicultura do Departamento de Zootecnia da Universidade Federal de Viçosa, em Viçosa - MG. Foram demarcadas 30 parcelas de $3 \times 3 \mathrm{~m}$, as quais receberam os tratamentos, que foram cinco doses de nitrogênio $\left(0,50,100,150\right.$ e $\left.200 \mathrm{~kg} \mathrm{ha}^{-1}\right)$, no período de janeiro a maio de 2006. O delineamento utilizado foi inteiramente casualizado, com seis repetições. Foi também utilizado a análise do teor de nitrogênio foliar $(\mathrm{N})$, em laboratório, como método de referência. Foram realizadas análises de regressão, com teste para a falta de ajuste, entre as variáveis estudadas (medidas de SPAD, N foliar e matéria seca) e o $\mathrm{N}$ aplicado. Também foi realizada a análise de correlação entre medidas de SPAD e N foliar. Os resultados mostraram que, exceto no primeiro período de aquisição dos dados, o SPAD foi capaz de detectar os efeitos das diferentes doses de N. As análises de correlação também mostraram que o medidor de clorofila pode ser considerado um indicador do status nutricional nessa forrageira.

Palavras-chave: adubação nitrogenada, forrageira, SPAD

\section{ABSTRACT \\ USE OF A PORTABLE CHLOROPHYLL METER TO DETECT DIFFERENT NUTRITIONAL STATUS IN Brachiaria decumbens}

Uniform fertilizer application as is used in conventional agrigulture is inefficient in the case of variable soil nutrition. Thus, the use of tools capable of identifying this variability may assist in site-specific application, allowing that each area receive the amount of fertilizer required. The objective of this work was to use a portable chlorophyll meter (SPAD 502 ) to detect different nutritional status resulting from different nitrogen fertilization rates in Brachiaria decumbens. This study was developed in a field already established with this forage, in the Forage Sector of the Department of Animal Science, Federal University of Viçosa, Brazil. Thirty plots measuring $3 \times 3 \mathrm{~m}$ were defined that received the treatments of five different rates of nitrogen fertilizer $\left(0,50,100,150\right.$ and $\left.200 \mathrm{~kg} \mathrm{ha}^{-1}\right)$ during the period of January to May of 2006. A completely random design with six replications was used. The nitrogen $(\mathrm{N})$ leaf content analysis in the laboratory was used as a reference method. Regression analysis were performed, with lack-of-fit test between the studied variables (SPAD measurements, N leaf content and dry matter) and applied N. A correlation analysis was also performed between SPAD measurements and leaf $\mathrm{N}$ content. The results showed that with the exception of the first acquisition period, the SPAD was capable of detecting the effects of the differents $\mathrm{N}$ application doses. The correlation analyses also indicated that the chlorophyll meter can be considered an indicator of nutritional status of this forage.

Keywords: nitrogen fertilization, forage, SPAD

\footnotetext{
Recebido para publicação em 23/01/2012. Aprovado em 14/02/2013.

1 - Eng $^{\circ}$ de Controle e Automação, Professor Adjunto da UFSJ/Ouro Branco-MG, mariocupertino@ufsj.edu.br

2 - Eng $^{\circ}$ Agrícola, Professor Associado da UFV, Viçosa-MG

3 - Eng ${ }^{\circ}$ Agrônomo, Professor Adjunto da UFG, Jataí-GO

4 - Eng ${ }^{\circ}$ Agrônomo, Professor Associado da UFV, Viçosa-MG
}

340 REVENG

340-350p. ENGENHARIA NA AgRiCUlturA, VIÇOSA - MG, V.21 N.4, JULHO / AGOSTO 2013 


\section{INTRODUÇÃO}

O Brasil destaca-se como exportador mundial de carne bovina, possuindo boa competitividade internacional, tendo como uma das principais causas deste feito o custo da produção ser relativamente menor em razão da alimentação ser predominantemente por pastagens (SOBER, 2012).

Com a elevação do custo da terra, o pecuarista está cada vez mais sendo obrigado a intensificar sua produção, tendo como influência fatores como o crescimento da renda populacional, da produção de grãos e de outros produtos da agroindústria. Esses efeitos provocam um deslocamento e/ou intensificação da exploração pecuária para locais distantes dos grandes centros, na procura de terras mais baratas, provocando aumento no custo dos insumos (PINHEIRO, 2002).

A adubação é uma das alternativas recomendadas para combater a baixa fertilidade e aumentar a produtividade em áreas de pastagens. Sendo assim, com o uso de fertilizantes, podese ter um aumento substancial na eficiência dos processos de crescimento e desenvolvimento na produção de forrageiras (GARCEZ NETO et al., 2002), maximizando lucro, reduzindo a susceptibilidade a doenças e ataques de pragas, elevando a qualidade da forragem, além de proporcionar reserva de energia (SCHRODER et al., 2000).

Com isso, diversos métodos vêm sendo desenvolvidos com intuito de se mensurar a quantidade dos nutrientes presentes no solo e nas plantas, para ser possível efetuar a recomendação necessária para futuras adubações.

Uma maneira prática de avaliar a condição nutricional de nitrogênio nas plantas tem sido através do medidor portátil de clorofila SPAD. O SPAD é um equipamento que fornece valores admensionais correlacionados com o teor de clorofila, além de ser de fácil uso e não ser destrutivo, ou seja, não sendo necessária a remoção das folhas das plantas para análise. É utilizado para medir indiretamente o teor de clorofila na folha e, consequentemente, indicar o status de nitrogênio, devido à proporcionalidade que este nutriente tem em relação à clorofila (COSTA et al., 2001).

Alguns trabalhos utilizando este equipamento vêm sendo desenvolvidos como o de Hussain et al. (2000), que utilizaram o medidor de clorofila para efetuar o gerenciamento de nitrogênio na cultura do arroz na Ásia. Outros pesquisadores utilizaram o medidor portátil de clorofila como ferramenta para medir o status nutricional de nitrogênio em plantas de feijão (CARVALHO et al., 2003; SORATTO et al., 2004).

Dessa forma, o objetivo desse trabalho consistiu em detectar diferentes status nutricionais relativos à diferentes doses de aplicação de nitrogênio em Brachiaria decumbens utilizando o medidor de clorofila SPAD 502.

\section{MATERIAL E MÉTODOS}

O experimento foi implantado no Setor de Forragicultura do Departamento de Zootecnia da Universidade Federal de Viçosa, em Viçosa MG, em uma área de pastagem estabelecida com Brachiaria decumbens. O clima local é do tipo tropical de altitude. O tipo de solo desta área era argiloso, a precipitação média mensal registrada durante o estudo foi de, aproximadamente, $110 \mathrm{~mm}$ e a temperatura média verificada foi por volta de $21{ }^{\circ} \mathrm{C}$.

Primeiramente efetuou-se a demarcação da área experimental e a amostragem de solo. Na Figura 1 ilustra a área experimental demarcada e no Quadro 1 estão apresentados os resultados das análises das amostras de solo.

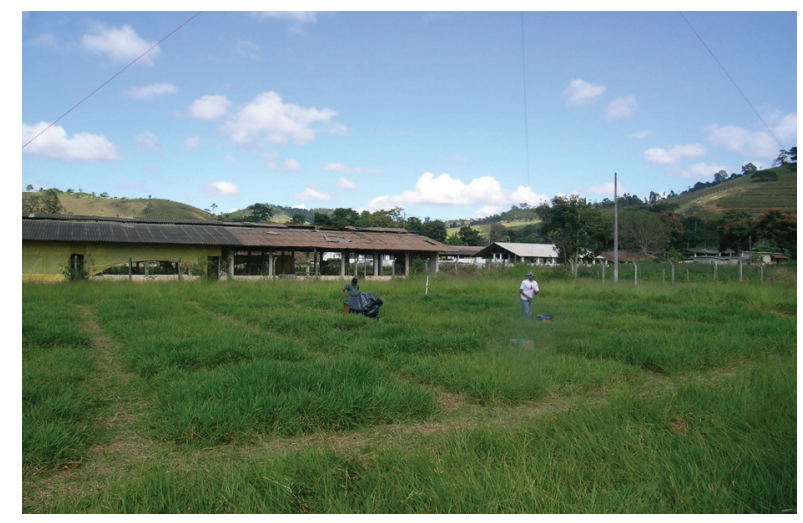

Figura 1. Vista geral da área experimental. 
Quadro 1. Resultados das análises físicas e químicas das amostras de solo.

\begin{tabular}{|c|c|c|c|c|c|c|c|c|c|c|c|c|c|c|}
\hline \multirow{2}{*}{ Ref. Lab. } & \multirow{2}{*}{\multicolumn{4}{|c|}{ Referência do Cliente }} & \multicolumn{2}{|r|}{$\mathrm{pH}$} & $\mathrm{P}$ & $\mathrm{K}$ & $\mathrm{Na}$ & $\mathrm{Ca}^{2+}$ & $\mathrm{Mg}^{2+}$ & \multicolumn{2}{|r|}{$\mathrm{Al}^{3+}$} & $\mathrm{H}+\mathrm{Al}$ \\
\hline & & & & & \multicolumn{2}{|c|}{$\mathrm{H}_{2} \mathrm{O}$} & ------- & $\mathrm{mg} / \mathrm{dm}^{3}$ & ----- & \multicolumn{5}{|c|}{ - $\mathrm{cmol}_{\mathrm{c}} / \mathrm{dm}^{3}$} \\
\hline 01 & & Solo A & grostolc & gia & 6, & 0 & 2,20 & 125,0 & - & 1,90 & 0,80 & & 0,0 & 3,96 \\
\hline \multirow[t]{2}{*}{ Ref. Lab. } & SB & $\begin{array}{c}\text { CTC } \\
\text { (t) }\end{array}$ & $\begin{array}{l}\text { CTC } \\
(\mathrm{T})\end{array}$ & $\mathrm{V}$ & $\mathrm{m}$ & ISNa & MO & P-rem & $\mathrm{Zn}$ & $\mathrm{Fe}$ & $\mathrm{Mn}$ & $\mathrm{Cu}$ & $\mathrm{B}$ & $\mathrm{S}$ \\
\hline & ---- & $\mathrm{cmol}_{\mathrm{c}} / \mathrm{dm}$ & $3^{3}---$ & ------ & $\%$ & ------ & dag $\mathrm{kg}^{-1}$ & $\mathrm{mg} \mathrm{L}^{-1}$ & $----\cdot$ & ------ & $--\mathrm{mg} / \mathrm{d}$ & & --------- & -------- \\
\hline 01 & 3,02 & 3,02 & 6,98 & 43 & 0 & - & 2,79 & 22,5 & 5,9 & 391,0 & 179,8 & 7,4 & 0,48 & 16,84 \\
\hline
\end{tabular}

$\mathrm{SB}$ (soma de Bases Trocáveis) $=\mathrm{K}^{+}+\mathrm{Ca}^{2+}+\mathrm{Mg}^{2+}$

$\mathrm{CTC}(\mathrm{T})$ (Capacidade de Troca Catiônica a pH7,0) $=\mathrm{SB}+(\mathrm{H}+\mathrm{Al})$

$\mathrm{CTC}(\mathrm{t})$ (Capacidade de Troca Catiônica Efetiva) $=\mathrm{SB}+\mathrm{Al}^{3+}$

$\mathrm{V}$ (Índice de Saturação de Bases $)=(\mathrm{SB} / \mathrm{T}) * 100$

$\mathrm{m}$ (Índice de Saturação de Alumínio $)=\left(100 * \mathrm{Al}^{3+}\right) / \mathrm{t}$

ISNa (Índice de Saturação de Sódio)

\begin{tabular}{ccccccc}
\multicolumn{7}{c}{ Resultados de Análises Granulométricos } \\
\hline \multirow{2}{*}{$\begin{array}{c}\text { Ref. } \\
\text { Lab. }\end{array}$} & \multirow{2}{*}{ Referência do Cliente } & Areia Grossa & Areia Fina & Silte & Argila & Classe \\
\cline { 3 - 6 } & & - Solo Agrostologia $_{01}$ & 12 & 17 & Textural \\
\hline
\end{tabular}
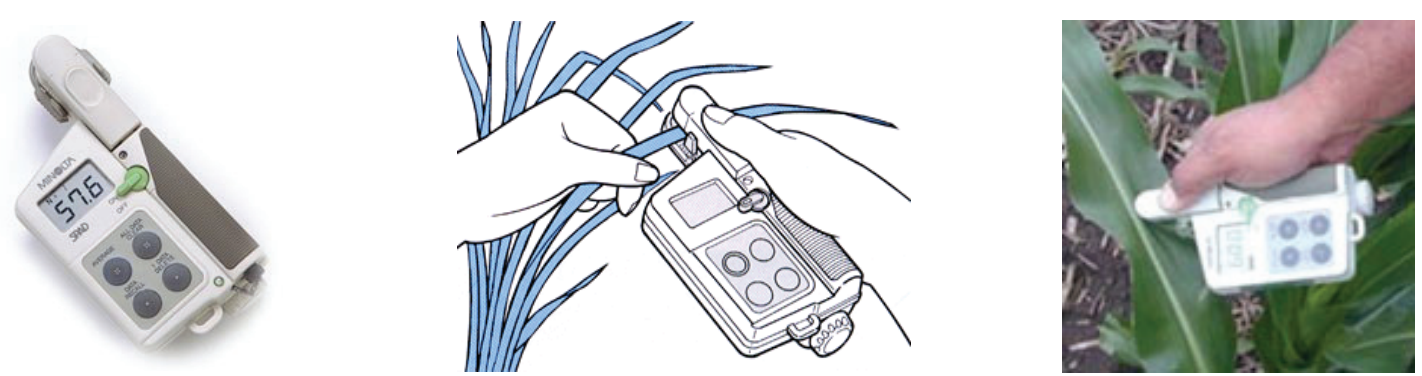

Figura 2. Medidor de clorofila SPAD 502.

Uma amostra de solo composta foi obtida de 20 amostras simples, coletadas na camada de 0 a $20 \mathrm{~cm}$, com distribuição espacial uniforme na área demarcada. Em seguida, efetuou-se um corte para uniformização das plantas de capim-braquiária a $10 \mathrm{~cm}$ de altura, utilizando uma segadora, com retirada da forragem da área.

A partir dos resultados das análises químicas e físicas das amostras de solo, foram aplicados, de acordo com o recomendado por Cantarutti et al. (1999), em cobertura, $50 \mathrm{~kg} \mathrm{ha}^{-1}$ de superfosfato simples, distribuídos uniformemente em toda a área experimental. Por fim, aplicou-se o adubo nitrogenado, na forma de uréia, correspondente a cada tratamento.

Os tratamentos consistiram de cinco doses de nitrogênio $\left(0,50,100,150\right.$ e $200 \mathrm{~kg} \mathrm{ha}^{-1}$ de nitrogênio) avaliadas em um delineamento inteiramente casualizado com seis repetições, perfazendo um total de 30 parcelas de $3 \times 3 \mathrm{~m}$.

Após a adubação com ureia, iniciou-se a primeira fase do experimento obtendo-se as estimativas do teor de clorofila, utilizando o medidor de clorofila SPAD 502 (Figura 2) e coletando-se folhas para análise do teor de nitrogênio foliar aos 15,21 e 32 dias após a adubação (DAA).

O princípio de operação do medidor de clorofila SPAD 502 é baseado na radiação transmitida pela folha, sendo esta, medida por dois sensores em dois comprimentos de onda: o primeiro mede na região do vermelho $(650 \mathrm{~nm})$ e o segundo mede a quantidade de luz transmitida na região do infravermelho próximo $(940 \mathrm{~nm})$ do espectro eletromagnético. Os sensores cobrem uma área de $2 \times 3 \mathrm{~mm}$ da

\section{REVENG


folha, que é uma relativamente pequena proporção do total de área da folha. Portanto, torna-se importante efetuar uma amostragem para aumentar a confiabilidade dos dados. A amostragem deve incluir folhas no mesmo estádio de crescimento e posição nas folhas, pois há diferença de planta para planta, entre diferentes idades das folhas e na variação da posição do equipamento na folha (SCHEPERS et al., 1998).

Aos 32 DAA, foi realizado o corte das plantas a $20 \mathrm{~cm}$ de altura do solo em uma área útil de $1 \mathrm{~m}^{2}$ dentro de cada parcela. Após a colheita a forragem foi pesada e retirada uma amostra de 300 a $500 \mathrm{~g}$ do capim, que foi colocada em sacos de papel, pesada e levada à estufa a $65{ }^{\circ} \mathrm{C}$ por 72 horas. Depois de secas, as amostras foram pesadas novamente e assim calculou-se a matéria seca produzida. Depois da amostragem no primeiro corte, a área não colhida da parcela (bordadura) também foi cortada a $20 \mathrm{~cm}$ do solo e iniciada uma segunda fase de avaliação, com reaplicação das mesmas doses de nitrogênio acrescidas de $60 \mathrm{~kg} \mathrm{ha}^{-1}$ de cloreto de potássio em todas as parcelas.

Devido à mudança no clima, nesta segunda fase, com redução de luminosidade e temperatura, a resposta das plantas à adubação deu-se de forma mais lenta, com isto a coleta dos valores de SPAD e das folhas para análise do teor de nitrogênio foliar foram nos períodos de 28, 36, 45 e 53 dias após a adubação (DAA).

Aos 53 DAA, foi realizado o corte das plantas, para medir a produtividade de matéria seca, utilizando os mesmo procedimentos da primeira fase.

Não foi necessário irrigar as plantas durante o período experimental, em razão da magnitude e distribuição adequadas da precipitação pluvial ocorrida durante o experimento. As plantas daninhas foram controladas manualmente em todas as parcelas, sempre que necessário.

Os valores estimados do teor de clorofila obtidos utilizando-se o medidor SPAD 502 e os valores obtidos pelo método de análise do teor de nitrogênio foliar, em laboratório, foram submetidos à análise estatística para testar a hipótese de discriminação dos status nutricionais, proporcionadas pelas diferentes doses de adubo nitrogenado. As análises estatísticas foram feitas, separadamente, para cada variável em cada um dos períodos após a aplicação do adubo.
Com isso, para efetuar as medições, posicionou-se a folha entre o emissor e receptor do equipamento, onde foram efetuadas 30 leituras no SPAD em cada parcela, sendo que cada valor foi medido em diferentes folhas ao longo de cada parcela, sendo escolhidas as mais novas e completamente expandidas, com o equipamento posicionado na sua porção intermediária. Após a obtenção dos 30 valores, calculou-se a média para representar o teor de clorofila de cada parcela.

$\mathrm{O}$ teor de $\mathrm{N}$ foliar foi utilizado para ser o método de referência em detectar os status nutricionais e também avaliar a correlação entre este método e o do medidor de clorofila SPAD.

Em cada parcela, as mesmas 30 folhas utilizadas para estimar o teor de clorofila com o medidor SPAD 502 foram, posteriormente, colhidas e acondicionadas em sacos de papel para determinar o teor de $\mathrm{N}$ em laboratório.

Foram efetuadas análises de regressão para verificar a existência de relação funcional significativa entre as variáveis dependentes (valores de SPAD e $\mathrm{N}$ foliar) e a variável independente (doses de N) em todos os períodos após a adubação analisados, utilizando o programa computacional Matlab (The MathWorks, EUA), versão 6.5, para desenvolver os algoritmos.

Os algoritmos efetuaram os cálculos dos testes F para a falta de ajustamento e análise de variância da regressão e para os testes dos coeficientes dos modelos, pelo teste t. Primeiramente, adotava-se o modelo de regressão linear simples, calculava-se a ANOVA e efetuava-se o teste $F$ para a falta de ajuste, em nível de $1 \%$ de probabilidade, para avaliar a qualidade do ajuste do modelo de regressão. Se o resultado fosse não significativo, indicava que o modelo era adequado e então se efetuava o teste $\mathrm{F}$, em nível de $1 \%$ de probabilidade, para a regressão, com intuito de verificar se a variação da variável independente influenciava significativamente na variação da variável dependente. Por fim, executava-se o teste $\mathrm{t}$ com $1 \%$ de probabilidade para analisar a significância do coeficiente do modelo $\left(\beta_{1}\right)$. Caso contrário, se o resultado do teste para falta de ajustamento fosse significativo, concluía-se que o modelo linear de primeiro grau era inadequado e, portanto efetuava-se novamente a mesma análise de variância, os testes $F$ para falta de ajustamento e para regressão, adotando o modelo de segundo grau. 
As variáveis SPAD e N foliar que proporcionaram um modelo de primeiro ou segundo grau adequado (resultado não significativo no teste $\mathrm{F}$ para falta de ajuste), e que também foram influenciadas pela variação das doses de $\mathrm{N}$ (resultado significativo no teste $\mathrm{F}$ para a regressão), foram consideradas como aptas para caracterizar diferentes status nutricionais nesta forrageira no período analisado. Já as variáveis que apresentaram resultado significativo no teste $F$ para falta de ajuste para os modelos de primeiro e segundo grau, foram consideradas como não aptas.

Não foram testados modelos superiores ao de segundo grau, por estes não representarem o fenômeno biológico da cultura, pois, em geral, a resposta com a elevação de doses de N é quadrática.

Outro método utilizado para avaliar a relação entre os valores de SPAD e $\mathrm{N}$ foliar em cada período de aquisição dos dados foi o método da correlação, que faz uso do coeficiente de correlação para determinar a relação entre duas propriedades. Este método também foi utilizado para avaliar as correlações significativas entre, SPAD com matéria seca (MS) e $\mathrm{N}$ foliar com matéria seca (MS), em nível de $1 \%$ de probabilidade, pelo teste $t$, sendo que a matéria seca (MS) foi produzida no último período avaliado de cada fase.

\section{RESULTADOS E DISCUSSÃO}

No Quadro 2 estão apresentados os modelos de primeiro ou segundo grau que foram ajustados, respectivamente, em todos os períodos desta fase experimental.

Aos 15 dias após a adubação (DAA), os valores das variáveis dependentes SPAD e $\mathrm{N}$ foliar não tiveram modelos de primeiro e segundo grau que se ajustassem aos dados. Este fato indica que, neste período de crescimento, as plantas ainda não apresentavam resposta significativa à adubação. Aos 21 e 32 DAA, as variáveis SPAD e $\mathrm{N}$ foliar indicaram que a variação dos valores de cada uma destas variáveis pôde ser explicada pela variação das doses aplicadas de $\mathrm{N}$ com modelos de segundo e primeiro grau, respectivamente, ou seja, a resposta à adubação nestes períodos foi detectada pelas medições de ambas variáveis, SPAD e $\mathrm{N}$ foliar.

As correlações entre o SPAD e o $\mathrm{N}$ foliar foram $0,92,0,95$ e 0,85 para os períodos 15,21 e 32 DAA, respectivamente. Aos 32 DAA, as correlações entre SPAD e MS e entre $\mathrm{N}$ foliar e MS foram 0,78 e 0,70 , respectivamente.

Quadro 2. Modelos ajustados aos valores das variáveis dependentes (SPAD, N foliar e MS) e coeficientes de determinação $\left(\mathrm{R}^{2}\right)$ aos 15, 21 e 32 dias após a adubação (DAA)

\begin{tabular}{ll}
\hline Modelos ajustados & $\mathbf{R}^{2}$ \\
\hline 15 DAA & \\
----- & \\
21 DAA & 0,96 \\
$\mathrm{SPAD}=34,55+0,14 \mathrm{~N}-3,11 \times 10^{-4} \mathrm{~N}^{2}$ & 0,97 \\
$\mathrm{~N}$ foliar $=1,62+0,01 \mathrm{~N}$ & \\
$\mathbf{3 2}$ DAA & 0,96 \\
$\mathrm{SPAD}=31,49+0,08 \mathrm{~N}$ & 0,87 \\
$\mathrm{~N}$ foliar $=1,42+0,04 \mathrm{~N}$ & 0,88 \\
$\mathrm{MS}=2,27+0,02 \mathrm{~N}$ & \\
\hline
\end{tabular}

SPAD: variável obtida pelo medidor de clorofila SPAD; $\mathrm{N}$ foliar: variável obtida pela análise do teor de $\mathrm{N}$ foliar em laboratório; MS: matéria seca produzida em toneladas por hectare; Os coeficientes $\beta_{1}$ e $\beta_{2}$ dos modelos ajustados foram significativos em nível de $1 \%$ de probabilidade pelo teste t "student". Os campos com "------." indicam ausência de modelo ajustado significativamente, pelo teste $\mathrm{F}$ em nível de $1 \%$ de probabilidade, e consequentemente ausência de coeficiente de determinação $\left(\mathrm{R}^{2}\right)$.

\section{REVENG}




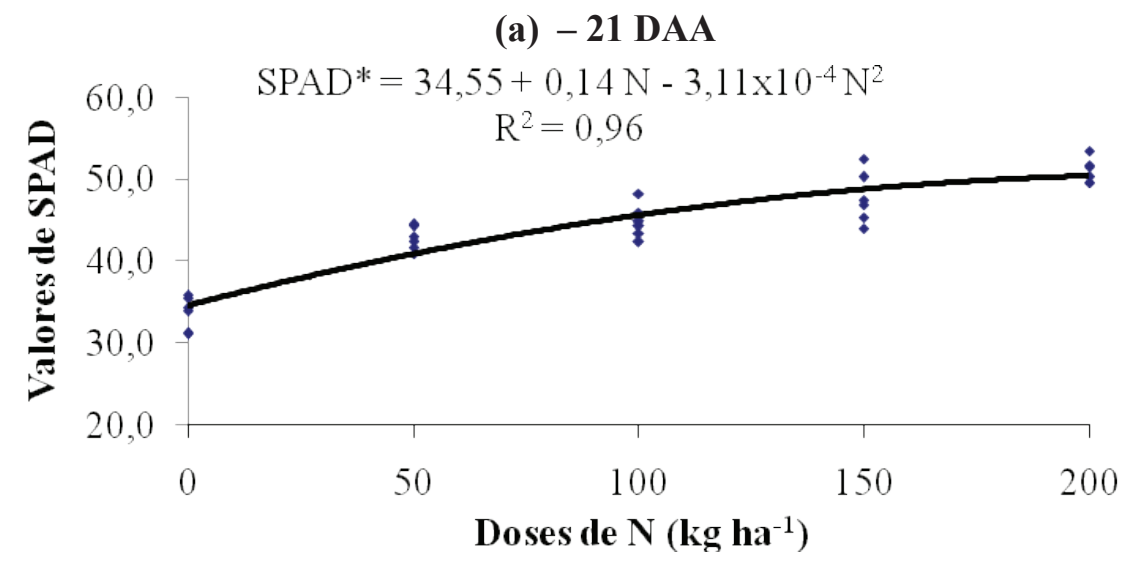

(a) Valores de SPAD em função das doses de N aplicadas em Brachiaria decumbens, aos 21 dias após a adubação (DAA), na primeira fase experimental.

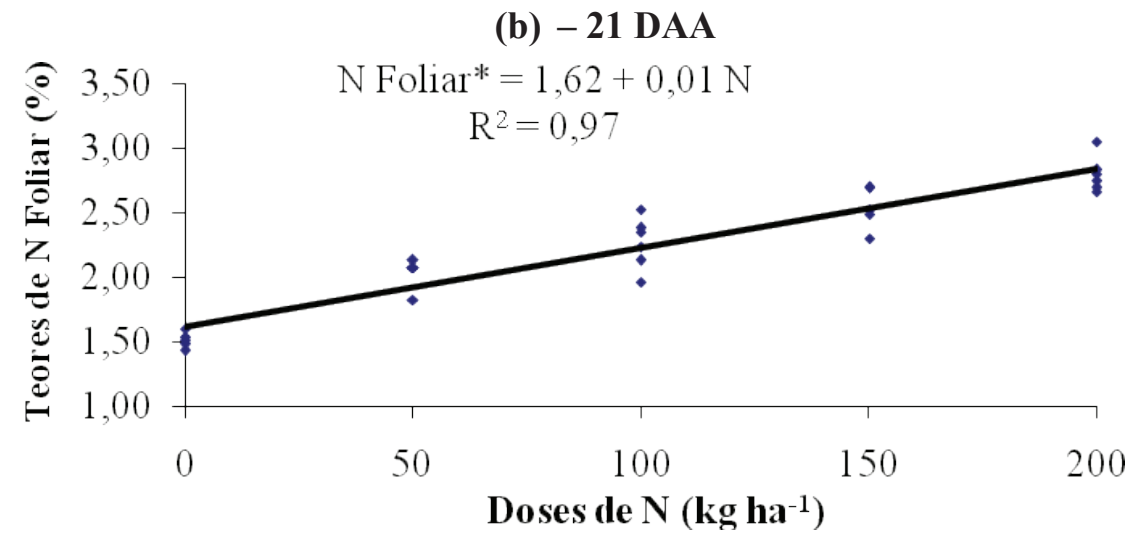

(b) Teores de $\mathrm{N}$ foliar em função das doses de $\mathrm{N}$ aplicadas em Brachiaria decumbens, aos 21 dias após adubação (DAA), na primeira fase experimental.

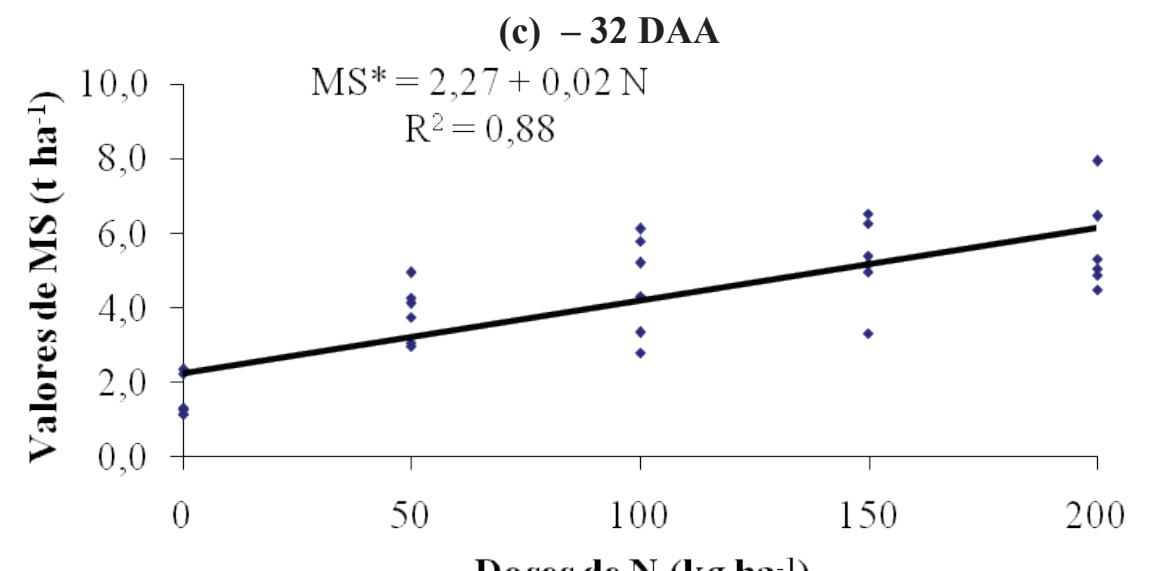

(c) Produção de matéria seca de Brachiaria decumbens em função das doses de $\mathrm{N}$ aplicadas, aos 32 dias após adubação (DAA), na primeira fase experimental.

Figura 3. Modelos ajustados, na primeira fase experimental, às variáveis: (a) SPAD aos 21 DAA, (b) N Foliar aos 21 DAA e (c) MS aos 32 DAA. * Significativo em nível de 1\% de probabilidade pelo teste t "student". 
Aos 21 DAA, foram observados os maiores valores de coeficiente de determinação e também o maior valor de correlação entre SPAD e N foliar, o que faz deste período, dentre os períodos estudados, o mais indicado para detectar os diferentes status nutricionais.

Observou-se um aumento gradativo dos valores SPAD com o aumento das doses de N, embora o incremento dos valores da variável SPAD, com o aumento da disponibilidade de $\mathrm{N}$, tenha sido maior nas menores doses. Este incremento foi diminuindo-se à medida que se aproximou-se das maiores doses, como ilustra a Figura 3(a). Esta tendência de redução dos incrementos dos valores estimados pelo SPAD, com altas doses de N, também foi verificada por outros autores (SCHEPERS et al., 1992; SCHRODER et al., 2000; LAVRES JUNIOR, 2001). Isto pode indicar que a cultura já estava entrando na região de adequação, com reflexos nos valores de SPAD, pois, segundo Schepers et al. (1998), quando a disponibilidade de $\mathrm{N}$ se aproxima do nível crítico, o teor de clorofila tende a se estabilizar.

Paulino et al. (1998), em um estudo com quatro cultivares de Panicum maximum (Aruana, Tanzãnia, Tobiatã e Vencedor), sob efeitos de três doses de nitrogênio $\left(0,80\right.$ e $\left.160 \mathrm{~kg} \mathrm{ha}^{-1}\right)$ e duas de fósforo (0 e $200 \mathrm{~kg} \mathrm{ha}^{-1}$ de $\mathrm{P}_{2} \mathrm{O}_{5}$ ), utilizaram o medidor de clorofila SPAD para determinar a produtividade das forrageiras e teores de nitrogênio. Os autores também observaram correlação linear positiva entre os teores de clorofila e doses de nitrogênio aplicadas, com coeficientes de correlação médios de 0,85 e de 0,87 entre as leituras em SPAD e o teor de nitrogênio. Conforme se aumentou à dose de nitrogênio na adubação, o verde das folhas recém-expandidas tornou-se mais intenso, sendo que os valores de leitura mostraram este fenômeno com bastante clareza. Na ausência de adubação nitrogenada, as folhas mostravam-se cloróticas em virtude da deficiência de nitrogênio, mostrando valores de leitura inferiores.

Entretanto, para a variável $\mathrm{N}$ foliar foi possível ajustar uma equação de primeiro grau em relação à dose de $\mathrm{N}$ aplicada, conforme ilustra a Figura 3(b), mostrando que não houve redução no incremento dos valores de $\mathrm{N}$ foliar até a maior dose estudada.
Nas Figuras 3(a) e (b) estão ilustrados os valores do SPAD e $\mathrm{N}$ foliar, respectivamente, em função das doses de $\mathrm{N}$ aos 21 dias após a adubação com as respectivas equações. Essa diferença no comportamento do incremento dos valores entre as variáveis SPAD e N foliar para as altas doses de $\mathrm{N}$ pode estar atrelada ao fato de que, ao efetuar-se uma medição com o SPAD, o resultado é um valor adimensional que leva em consideração outros fatores além do N. Já com a análise laboratorial do $\mathrm{N}$ presente na folha, restringiu-se à avaliação somente a este nutriente.

Com relação à matéria seca (MS) produzida aos 32 DAA, os valores desta variável em toneladas por hectare em função de doses de $\mathrm{N}$ são ilustrados pela Figura 3(c). Observou-se que, para cada 50 $\mathrm{kg}$ de $\mathrm{N}$ aplicado, a produção de MS aumentou, aproximadamente, 1 tonelada.

Cunha (2004) encontrou valores de produtividade de matéria seca no capim-Tanzânia entre 0,70 e $4,30 \mathrm{t} \mathrm{ha}^{-1}$, para a variação de $0 \mathrm{a}$ $2.079 \mathrm{~kg} \mathrm{ha}^{-1}$ ano $^{-1}$ de $\mathrm{N}$, respectivamente, sendo esta relação obtida por uma equação polinomial quadrática. $\mathrm{O}$ autor verificou também que o uso de doses superiores a $756 \mathrm{~kg} \mathrm{ha}^{-1}$ ano $^{-1}$ de $\mathrm{N}$ não proporcionaram efeitos positivos sobre a produção de matéria seca.

Ao contrário do verificado por Cunha (2004), não foi encontrada região de adequação no gráfico da Figura 3(c), que, de acordo com Martinez et al. (1999), é a região onde o aumento do suprimento do nutriente e seu teor nos tecidos não são acompanhados por um aumento proporcional no crescimento ou produção. Indicando que, até a aplicação de $200 \mathrm{~kg} \mathrm{ha}^{-1}$, o nutriente foi convertido em aumento da produção de massa seca.

No Quadro 3 estão os modelos de primeiro ou segundo grau que foram ajustados em todos os períodos de aquisição da segunda fase experimental.

Observou-se, nesta fase experimental, que os dados de todas as variáveis dependentes, em todos os períodos de avaliações, apresentaram modelos ajustados ao primeiro ou segundo grau, indicando que em todos estes períodos estudados foi possível detectar os diferentes status nutricionais, causados pelo efeito da adubação nitrogenada, pelas variáveis SPAD e N foliar. 
Quadro 3. Modelos ajustados aos valores das variáveis dependentes (SPAD, N foliar e MS) e coeficientes de determinação $\left(\mathrm{R}^{2}\right)$ aos 28, 36, 45 e 53 dias após adubação (DAA)

\begin{tabular}{ll}
\hline Modelos ajustados & $\mathbf{R}^{2}$ \\
\hline $\mathbf{2 8}$ DAA & \\
$\mathrm{SPAD}=33,57+0,18 \mathrm{~N}-4,7 \times 10^{-4} \mathrm{~N}^{2}$ & 0,99 \\
$\mathrm{~N}$ foliar $=1,70+0,01 \mathrm{~N}$ & 0,95 \\
$\mathbf{3 6}$ DAA & \\
$\mathrm{SPAD}=35,35+0,08 \mathrm{~N}$ & 0,96 \\
$\mathrm{~N}$ foliar $=1,60+0,01 \mathrm{~N}$ & 0,99 \\
$\mathbf{4 5} \mathbf{D A A}$ & \\
$\mathrm{SPAD}=33,46+0,08 \mathrm{~N}$ & 0,99 \\
$\mathrm{~N}$ foliar $=1,45+0,01 \mathrm{~N}$ & 0,97 \\
$\mathbf{5 3} \mathbf{D A A}$ & \\
$\mathrm{SPAD}=31,21+0,07 \mathrm{~N}$ & 0,99 \\
$\mathrm{~N}$ foliar $=1,47-1,70 \times 10^{-3} \mathrm{~N}+2,6667 \times 10^{-5} \mathrm{~N}^{2}$ & 0,89 \\
$\mathrm{MS}=1,36+0,02 \mathrm{~N}$ & 0,97 \\
\hline
\end{tabular}

SPAD: variável obtida pelo medidor de clorofila SPAD; $\mathrm{N}$ foliar: variável obtida pela análise do teor de $\mathrm{N}$ foliar em laboratório; MS: matéria seca produzida em toneladas por hectare; Os coeficientes $\beta_{1}$ e $\beta_{2}$ dos modelos ajustados foram significativos em nível de $1 \%$ de probabilidade pelo teste t "student".

Aos 36 e 45 DAA, foram encontrados os maiores valores de $\mathrm{R}^{2}$ para o $\mathrm{N}$ foliar e SPAD, respectivamente, indicando que nestes períodos os modelos puderam representar melhor o efeito da adubação diferenciada sobre as variáveis estudadas.

Os valores de correlação entre SPAD e N foliar aos 28, 36, 45 e 53 DAA foram 0,91, 0,87, 0,91 e 0,83 , respectivamente. Aos 53 DAA, o valor de correlação obtido entre SPAD e MS foi de 0,7564 e entre $\mathrm{N}$ foliar e MS foi de 0,59 . Todos estes valores de correlações também foram significativos em nível de $1 \%$ de probabilidade, pelo teste t. Comparando estes valores de correlação com os obtidos na primeira fase, verificou-se que mesmo ocorrendo a detecção dos status nutricionais em todos os períodos após a adubação estudados, em geral, os valores tenderam a reduzir, mostrando a diminuição das relações entre estas variáveis. Esta menor correlação provavelmente é devida à mudança climática verificada nesta segunda fase, que propiciou menor resposta das plantas à adubação nitrogenada, dificultando o discernimento entre os tratamentos. Entretanto, esta menor resposta das plantas não foi suficiente para impedir a detecção dos diferentes status proporcionados pelas doses de $\mathrm{N}$ aplicadas.
Os valores de SPAD e de $\mathrm{N}$ foliar ajustaram-se à modelos lineares positivos em função das doses de $\mathrm{N}$ aos 45 e 36 DAA, cujos valores de $\mathrm{R}^{2}$ foram os maiores desta fase experimental (Figuras 4 (a) e (b)).

Costa et al. (2001) também obtiveram sucesso utilizando este medidor na avaliação do status de nitrogênio em folhas de planta de milho, em um experimento conduzido durante 1996 e 1997, em Ottawa e Montreal, no Canadá. Foram testadas as doses de nitrogênio $\left(0,85,170\right.$ e $\left.255 \mathrm{~kg} \mathrm{ha}^{-1}\right)$ em seis genótipos de milho e todos mostraram aumento nos valores das leituras do medidor SPAD e da clorofila, os quais correlacionaram significativamente com as doses de nitrogênio.

Esta resposta linear positiva também foi observada por Sena Junior (2005), em experimento com diferentes doses de $\mathrm{N}$ em trigo cultivado em vasos, para os valores de SPAD e N foliar. O mesmo autor também verificou aumento linear nos valores de SPAD e de $\mathrm{N}$ foliar até a maior dose aplicada (120 kg ha-1 de $\mathrm{N}$ ), indicando que não se atingiu o ponto de estabilização nos teores de clorofila e que o $\mathrm{N}$ pode estar sendo acumulado nas folhas, em outras formas. 


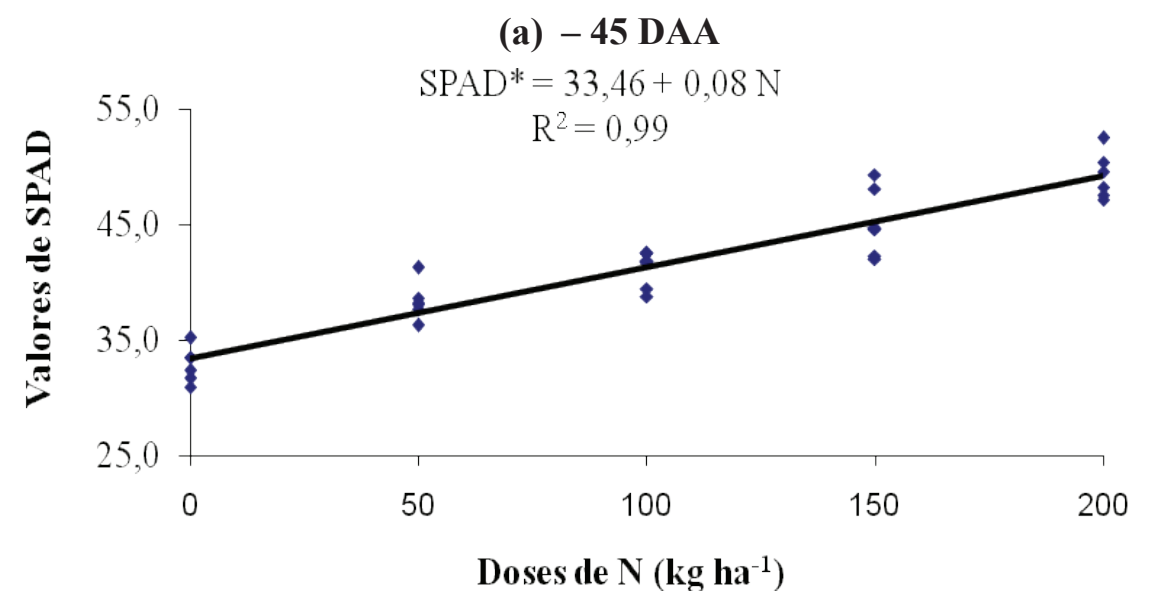

(a) Valores de SPAD em função das doses de $\mathrm{N}$ aplicadas em Brachiaria decumbens, aos 45 dias após adubação (DAA), na segunda fase experimental.

\section{(b) - 36 DAA}

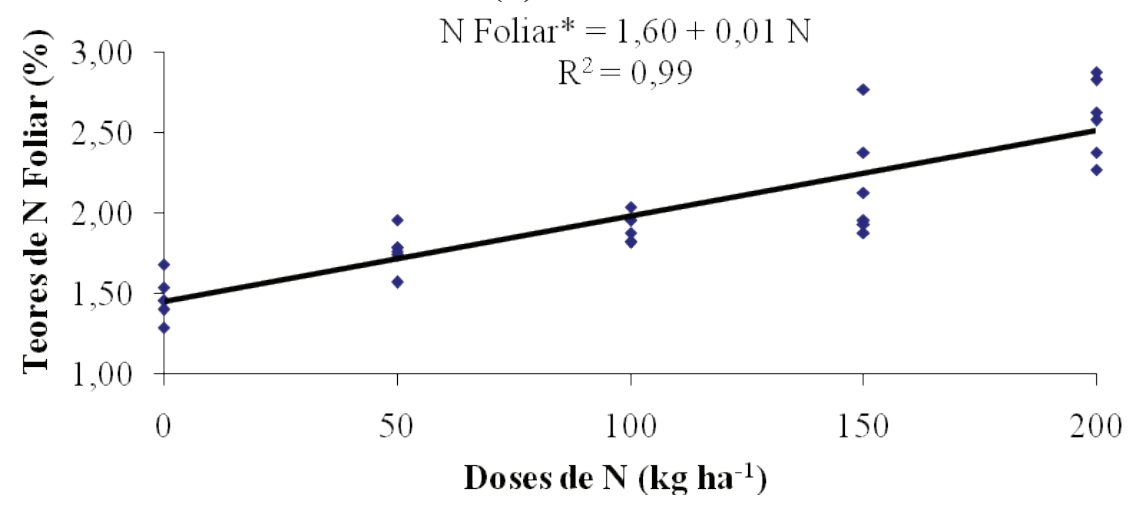

(b) Teores de $\mathrm{N}$ foliar em função das doses de $\mathrm{N}$ aplicadas em Brachiaria decumbens, aos 36 dias após adubação (DAA), na segunda fase experimental.

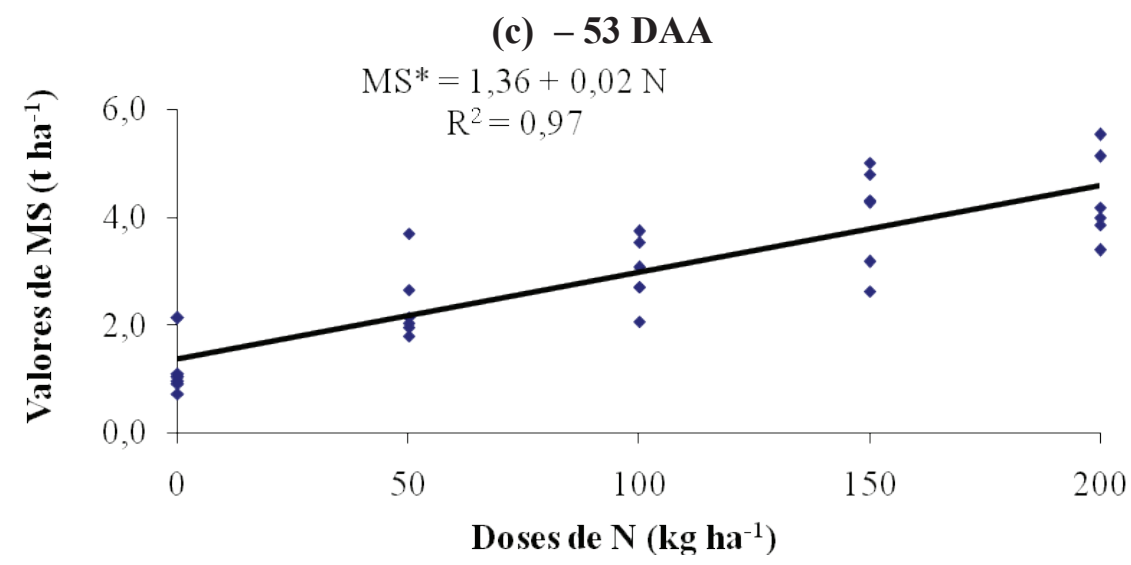

(c) Produção de matéria seca de Brachiaria decumbens em função das doses de $\mathrm{N}$ aplicadas, aos 53 dias após adubação (DAA), na segunda fase experimental.

Figura 4. Modelos ajustados, na segunda fase experimental, às variáveis: (a) SPAD aos 45 DAA, (b) N Foliar aos 36 DAA e (c) MS aos 53 DAA. * Significativo em nível de 1\% de probabilidade, pelo teste $t$ "student".

\section{REVENG}


Os dados de produção de MS aos 53 DAA também se ajustaram a modelos lineares positivos em função das doses de N (Figura 4(c)).

Observou-se um aumento de cerca de 0,8 tonelada por hectare de massa seca para cada $50 \mathrm{~kg}$ $\mathrm{ha}^{-1} \mathrm{de} \mathrm{N}$ aplicados. Este aumento foi menor do que o encontrado na fase anterior. Isto já era esperado, visto que, nesta segunda fase, ocorreram mudanças climáticas desfavoráveis ao desenvolvimento da forrageira.

Cunha (2004), em experimento conduzido em uma área cultivada com capim-Tanzânia, observou que, independente das lâminas de irrigação e das doses de nitrogênio aplicadas, a produtividade de matéria seca foi menor no período seco e maior no período úmido, concluindo que fatores climáticos como a radiação solar e a temperatura influenciaram nos resultados. Este período, considerado como seco, é identificado pela diminuição da radiação solar e da temperatura, com isso o autor encontrou menores valores de produção de matéria seca (MS) do capim-Tanzânia, em todas as doses de N utilizadas, em relação aos valores encontrados no período úmido, com os valores variando de 0,20 a $1,00 \mathrm{t} \mathrm{h}^{-1}$ entre as doses mínima e máxima de $0 \mathrm{a}$ $2.079 \mathrm{~kg} \mathrm{ha}^{-1} \mathrm{ano}^{-1} \mathrm{de} \mathrm{N}$, respectivamente.

\section{CONCLUSÕES}

- O medidor de clorofila SPAD 502 demonstrou, neste estudo, ser um eficiente estimador do teor de nitrogênio foliar e foi capaz de detectar diferentes status nutricionais, em diferentes períodos após a adubação;

- Dentre os periodos testados, apenas aos 15 dias após a adubação (DAA) não seria indicado para tentar detectar os diferentes status nutricionais usando o SPAD e N foliar;

- O medidor de clorofila também demonstrou ter potencial para a predição da produção de matéria seca nas duas fases experimentais estudadas.

\section{AGRADECIMENTOS}

À Coordenação de Aperfeiçoamento de Pessoal de Nível Superior (Capes), à Fundação de Amparo à Pesquisa do Estado de Minas Gerais (Fapemig) e ao Conselho Nacional de Desenvolvimento Científico e Tecnológico (CNPq), pela concessão da bolsa de estudos e pelo financiamento da presente pesquisa.

\section{REFERÊNCIAS BIBLIOGRÁFICAS}

CANTARUTTI, R.B.; MARTINS, C.E.; CARVALHO, M.M.; FONSECA, D.M.; ARRUDA, M.L.; VILELA, H.; OLIVEIRA, F.T.T. Pastagens. In: RIBEIRO, A.C.; GUIMARÃES, P.T.G.; ALVAREZ, V.H. Recomendações para o Uso de Corretivos e Fertilizantes em Minas Gerais - 5a Aproximação. Viçosa: UFV, 1999, p.332-341.

CARVALHO, M.A.C.; FURLANI JUNIOR, E.; ARF, O.; SÁ, M.E.; PAULINO, H.B.; BUZETTI, $\mathrm{S}$. Doses e épocas de aplicação de nitrogênio e teores foliares deste nutriente e de clorofila em feijoeiro. Revista Brasileira de Ciência do Solo, v.27, p.445-450, 2003.

COELHO, A.M. Potencial de utilização das técnicas de agricultura de precisão na recuperação da fertilidade dos solos sob pastagens degradadas. Circular Técnica, Sete Lagoas, n.68, p.8, 2005.

COSTA, C.; DWYER, L.M.; DUTILLEUL, P.; STEWART, D.W.; MA, B.L.; SMITH, D.L. Inter-relationships of applied nitrogen, spad, and yield of leafy and non-leafy maize genotypes. Journal of Plant Nutrition, v.24, n.8, p.11731194, 2001.

CUNHA, C.A.H. Relação entre comportamento espectral, índice de área foliar e produção de matéria seca em capim Tanzânia submetido a diferentes níveis de irrigação e doses de nitrogênio. $154 \mathrm{f}$. Tese (Doutorado em Agronomia) - ESALQ, Piracicaba, 2004.

GARCEZ, N.A.F.; NASCIMENTO JUNIOR, D.; REGAZZI, A.J.; FONSECA, D.M.; MOSQUIM, P.R.; GOBBI, K.F. Respostas morfogênicas e estruturais de Panicum maximum cv. mombaça sob diferentes níveis de adubação nitrogenada e alturas de corte. Revista Brasileira de Zootecnia, v.31, n.5, p.1890-1900, 2002. 
GUIMARÃES, T.G.; FONTES, P.C.R.; PEREIRA, P.R.G.; ALVAREZ, V.H.; MONNERAT, P.H. Teores de clorofila determinados por medidor portátil e sua relação com formas de nitrogênio em folhas de tomateiro cultivados em dois tipos de solo. Bragantia, Campinas, v.58, n.1, p.209-216, 1999.

HUSSAIN, F.; BRONSON, K.F.; YADVINDERSINGH, B.S.; PENG, S. Use of Chlorophyll Meter Sufficiency Indices for Nitrogen Management of Irrigated Rice in Asia. Agronomy Journal, v.92, p.875-879, 2000.

LAVRES JUNIOR, J. Combinações de doses de Nitrogênio e Potássio para o Capim-Mombaça. 2001. 103 f. Dissertação (Mestrado em Agronomia) - ESALQ, Piracicaba, 2001.

MARTHA JUNIOR, G.B.; VILELA, L. Pastagens no Cerrado: Baixa Produtividade pelo Uso Limitado de Fertilizantes. Documentos 50, Planaltina: Embrapa Cerrados, p.32, 2002.

MARTINEZ, H.E.P.; CARVALHO, J.G.; SOUZA, R.B. Diagnose foliar. In: RIBEIRO, A.C.; GUIMARÃES, P.T.; ALVAREZ, V.H. Recomendações para o uso de corretivos e fertilizantes em Minas Gerais - $5^{\text {a }}$ aproximação. Viçosa: UFV, 1999, p.143-168.

PAULINO, V.T.; SCHUNKE, R.; CANTARELLA, H. Avaliação do nível de nitrogênio em quatro cultivares de Panicum maximum Jacq. através da medida indireta de clorofila. In: REUNIÃO ANUAL DA SOCIEDADE BRASILEIRA DE ZOOTECNIA, 35., 1998, Botucatu. Anais... Botucatu: Sociedade Brasileira de Zootecnia, 1998. p.508-511.

PINHEIRO, V.D. Viabilidade econômica da irrigação de pastagem de capim Tanzânia em diferentes regiões do Brasil. 2002. 85f. Dissertação (Mestrado em Agronomia) - ESALQ, Piracicaba, 2002.
SCHEPERS, J.S.; BLACKMER, T.M.; FRANCIS, D.D. Chlorophyll meter method for estimating nitrogen concentration content in plant tissue. In: KALRA, Y.P. Handbook of reference methods for plant analysis, CRC Press, Boca Raton, FL, p.129-135, 1998.

SCHEPERS, J.S.; FRANCIS, D.D.; VIGIL, M.; BELOW, F.E. Comparison of corn leaf nitrogen concentration and chlorophyll meter readings. Communications in Soil Science and Plant Analysis, v.23, p.2173-2187, 1992.

SCHRODER, J.J.; NEETESON, J.J.; OENEMA, O.; STRUIK, P.C. Does the crop or the soil indicate how to save nitrogen in maize production? Reviewing the state of the art. Field Crops Research, v.66, p.151-164, 2000.

SENA JUNIOR, D.G. Utilização de técnicas de visão artificial para ajuste da adubação nitrogenada em trigo. 2005. 149f. Tese (Doutorado em Engenharia Agrícola) - UFV, Viçosa, 2005.

SILVA JÚNIOR, M.C. Deteç̧ão do efeito da adubação nitrogenada em Brachiaria decumbens utilizando técnicas de sensoriamento remoto. 2006. 96f. Dissertação (Mestrado em Engenharia Agrícola) - UFV, Viçosa, 2006.

SOBER (Sociedade Brasileira de Economia, Administração de Sociologia Rural), 2009. Disponível em: < http://www.sober.org.br/ palestra/13/356.pdf $>$. Acesso em: 25 nov 2012.

SORATTO, R.P.; CARVALHO, M.A.C.; ARF, O. Teor de clorofila e produtividade do feijoeiro em razão da adubação nitrogenada. Pesquisa Agropecuária Brasileira, Brasília, v.39, n.9, p.895-901, 2004. 